\title{
Magnesium Transport in the Cortical Thick Ascending Limb of Henle's Loop of the Rabbit
}

\author{
G. Reza Shareghi and Zalman S. Agus, Renal-Electrolyte Section, Department of \\ Medicine, University of Pennsylvania School of Medicine, Philadelphia, \\ Pennsylvania 19104
}

A B S T R A C T Isolated cortical thick ascending limbs of Henle's loop were perfused in order to directly evaluate magnesium transport in this segment. Transepithelial potential difference was altered by varying the $\mathrm{NaCl}$ concentration in perfusate and bath and adding $50 \mu \mathrm{M}$ furosemide to the perfusate. Perfusion under standard conditions with isotonic solutions resulted in a mean transepithelial potential difference of $+8.8 \pm 0.7 \mathrm{mV}$ and net magnesium absorption at a rate of $0.32 \pm 0.06 \mathrm{pmol} / \mathrm{mm}$ per min. Perfusion with a hypotonic solution significantly increased potential difference and the net absorptive rate of magnesium, calcium, and potassium. Conversely, reversal of the polarity of the potential difference with low $\mathrm{NaCl}$ bath and luminal furosemide produced net secretion of magnesium, calcium, and potassium. Parathyroid hormone in a bath concentration of $1.0 \mathrm{U} / \mathrm{ml}$ increased magnesium absorption from $0.34 \pm 0.06$ to $0.63 \pm 0.06$ $\mathrm{pmol} / \mathrm{mm}$ per min $(P<0.001)$ and calcium from $0.52 \pm 0.08$ to $0.97 \pm 0.08 \mathrm{pmol} / \mathrm{mm}$ per min $(P$ $<0.001$ ). Dibutyryl cyclic AMP produced similar effects on both calcium and magnesium absorption. Increasing bath calcium concentration twofold significantly inhibited net calcium absorption from $0.79 \pm 0.27$ to $0.16 \pm 0.02 \mathrm{pmol} / \mathrm{mm}$ per min but magnesium transport was unaffected. Increasing bath magnesium concentration twofold significantly inhibited net magnesium absorption from $0.56 \pm 0.14$ to $-0.09 \pm 0.13 \mathrm{pmol} / \mathrm{mm}$ per min but had no effect upon net calcium transport. Net absorption of magnesium was significantly increased with increased concentra-

Portions of this study were presented at the 12th Annual Meeting of the American Society of Nephrology, Boston, MA, November 20,1979 and were published in abstract form in 1979. (Proceedings of the 12th Annual Meeting of the American Society of Nephrology. 67a; Clin. Res. 27: 430a.)

Dr. Agus is the recipient of a National Institutes of Health Research Career Development Award (5-K04-AM 00258). Dr. Shareghi received a fellowship from the National Kidney Foundation. Address reprint requests to Dr. Agus.

Received for publication 14 September 1981 and in revised form 16 November 1981. tion in the perfusate but calcium transport was unchanged. Similarly, increasing perfusate calcium concentration produced an increase in net calcium transport but did not alter magnesium transport. These data indicate that this segment of the loop of Henle is an important site for magnesium transport. Transport is influenced by luminal and bath concentration and is stimulated by parathyroid hormone and cyclic AMP. The data do not provide support for the concept of an interactive process between calcium and magnesium, and suggest that the positive transepithelial voltage is an important driving force for net reabsorption of magnesium, as well as calcium and potassium in this segment.

\section{INTRODUCTION}

The kidney plays a major role in the regulation of the extracellular magnesium concentration. Previous studies of sites of transport within the kidney using micropuncture techniques have suggested that the middle segment of the nephron-pars recta and loop of Henle-is the major segment responsible for reabsorption of the bulk of the filtered load of magnesium (14). Although there are no direct studies of magnesium transport in the pars recta, data obtained from descending limb micropuncture suggested that the ascending limb of the loop of Henle was the important site $(2,5)$.

The mechanism of transport in this segment has not been directly evaluated, but recent studies in the rat using in vivo perfusion of the pars recta and loop of Henle (6-8) have demonstrated that reabsorption is increased by parathyroid hormone (PTH) ${ }^{1}$ and luminal magnesium concentration but inhibited by both hypermagnesemia and hypercalcemia. These studies and others have suggested an interaction between the

${ }^{1}$ Abbreviations used in this paper: CTALH, cortical thick ascending limb of Henle's loop: PD, potential difference; PTH, parathyroid hormone. 
transport of calcium and magnesium. Because of the different effects of increasing luminal magnesium and hypermagnesemia, and because of similarities between calcium and magnesium transport in this segment, it has been postulated that absorption of magnesium in the thick ascending limb is characterized by passive uptake at the luminal membrane and a competitive interaction with calcium at the contraluminal membrane (9).

The present experiments using isolated tubule perfusion were designed to characterize directly the mechanisms of magnesium transport in the cortical thick ascending limb of Henle's loop (CTALH), and to evaluate the effects of transepithelial potential difference (PD), PTH, dibutyryl cyclic AMP, and changes in luminal as well as bathing solution concentrations of calcium and magnesium.

\section{METHODS}

\section{Techniques}

Tubules were perfused using the techniques of isolated tubular perfusion developed by Burg and co-workers (10) and modified by Shareghi and Stoner (11). Briefly, kidneys of New Zealand White female rabbits maintained on rabbit chow (Ralston Purina Co., St. Louis, MO) were removed immediately after decapitation of rabbits by guillotine. Slices 1-3 mm thick were cut along the corticomedullary axis of the tissue and then slices were further cut perpendicular to the corticomedullary axis at the junction of the cortex and outer medulla. Cortical slices were then dissected while immersed in the isotonic bath solution at room temperature. CTALH were transferred to the perf usion chamber and perfused at $39^{\circ} \mathrm{C}$ using concentric glass pipettes. The pipette system is similar to that previously described (11) providing a means of changing perfusion fluid with the tubule in place, Sylgard 184 liquid dielectric (Dow Corning Corp., Midland, MI) in the outside pipette of the collecting end and a volumetric constriction pipette for fluid collection.

The perfusate and bath ionic composition are defined in Table I. Perfusion solution $A$ and bath solution $C$ are standard isotonic solutions. Perfusion solution B was hypotonic, containing about $59 \mathrm{mM}$ sodium and chloride, while bath solution D contained $38 \mathrm{mM}$ sodium and $8 \mathrm{mM}$ chloride, brought to isotonicity with $200 \mathrm{mM}$ mannitol. All the perfusion solutions were brought to $\mathrm{pH} 7.4$ by addition of a few drops of $0.15 \mathrm{M} \mathrm{HCl}$ or $0.15 \mathrm{M} \mathrm{NaOH}$. The bath $\mathrm{pH}$ was kept at 7.4 during the experiment by continuous vigorous bubbling with a $95 \% \mathrm{O}_{2}-5 \% \mathrm{CO}_{2}$ gas mixture. Tubules were warmed to $39^{\circ} \mathrm{C}$ and the chamber temperature maintained with a thermistor probe and a temperature controller (model 73A, Yellow Springs Instrument Co., Yellow Springs, $\mathrm{OH}$ ) attached to a heating filament embedded in the chamber. Collections were begun $\sim 30$ min after beginning perfusion at $39^{\circ} \mathrm{C}$. Perfusion was carried out at $2-9 \mathrm{nl} / \mathrm{min}$ and regulated by adjusting the height of the column of perfusion fluid. Timed collections of fluid emerging from the tubular lumen averaging 3-10 $\mathrm{min}$ in duration were made under water saturated mineral oil with a precalibrated constriction pipette.

The perfusion pipette served as a luminal electrode and was connected to a calomel half-cell through a $0.16 \mathrm{M} \mathrm{NaCl}$ -
4\% agar bridge. The calomel half-cell was connected to an electrometer (Keithley Instruments, Inc., Cleveland, $\mathrm{OH}$ ) and the circuit completed through a $0.16 \mathrm{M} \mathrm{NaCl}-4 \%$ agar bridge connecting the bath to a reference calomel half-cell connected to ground.

Sodium, potassium, chloride, calcium, phosphate, and magnesium concentrations in bulk solutions were analyzed daily using flame photometry, a chloridometer, autoanalyzers and atomic absorption spectrometry as previously described (12). Simultaneous samples from bath, perfusate, and collected tubular fluid were processed immediately and analyzed in six replicates of $0.3-\mathrm{nl}$ samples using the technique of electron probe microanalysis as previously described from this laboratory (12). Osmolality of bath and perfusion fluid was determined with an Osmette Precision Osmometer (Precision Systems, Inc., Sudbury, MA) and pH with a Beckman pH meter (Beckman Instruments, Inc., Fullerton, CA).

The bath solutions were completely changed every 7-10 min throughout the experiment to maintain a constant osmolality. Tubular leaks were monitored by the use of [meth $o x y-{ }^{3} \mathrm{H}$ ]inulin (New England Nuclear, Boston, MA) in the perfusate. [ $m e t h o x y-{ }^{3} \mathrm{H}$ ] Inulin was dialyzed before use against distilled water for 12-18 $\mathrm{h}$ at room temperature, and the radioactivity in perfusate and collected fluid was measured with liquid scintillation spectrometry as previously described (12). Any tubule with an inulin leak of $2 \%$ or more, as estimated by the ratio of concentration of inulin in collected fluid to perfusate, was excluded from analysis. Tubular length was measured during perfusion with a calibrated reticle in the ocular of the microscope.

\section{Protocols}

After the initial $30 \mathrm{~min}$ of perfusion, for equilibration, the tubules were studied according to the following protocols.

Controls. Nine tubules were studied for three consecutive 40-min periods. These tubules were perfused with isotonic perfusion solution $A$ and bathed with isotonic solution $C$ (Table I). These tubules provide a time control for subsequent studies.

Effects of $P D$. In these series of experiments the effects of a wide variety of transepithelial PD on net transport rates of calcium, magnesium, and potassium were studied. To achieve a wide range of positive and negative luminal potentials with respect to the bath, we took advantage of the ionic and permeability properties of this segment, similar to previously reported studies by Bordeau and Burg (13).

Normally in CTALH the lumen potential is positive with respect to the bath due to a voltage generated by active chloride transport out of the lumen and a dilution potential secondary to $\mathrm{NaCl}$ absorption along the length of the tubule. This latter potential is caused by the greater permeability of CTALH to sodium than to chloride. To increase the lumen positive potential therefore we used perfusate solution B (Table I) containing $\sim 59 \mathrm{mM} \mathrm{NaCl}$, a concentration that approximates the limit of the diluting ability of CTALH in vitro (14), and therefore should maximize the dilution potential. To achieve a negative luminal voltage, active chloride transport and its resultant positive luminal potential were abolished by luminal $50 \mu \mathrm{M}$ furosemide (15) and the polarity of dilution potential was reversed by perfusing tubules with solution $\mathrm{A}$ and bath solution $\mathrm{D}$ (Table I) contain ing $38 \mathrm{mM} \mathrm{Na}$ and $200 \mathrm{mM}$ mannitol to maintain isotonicity.

In one set of experiments six tubules were perfused and bathed in a random sequence with the following solution combinations: isotonic perfusion (perfusion $\mathrm{A}$ and bath $\mathrm{C}$ ), isotonic, low $\mathrm{NaCl}$ bath (perfusion $\mathrm{A}$ and bath $\mathrm{D}$ ), or hy- 
potonic low $\mathrm{NaCl}$ perfusion (perfusion $\mathrm{B}$ and bath $\mathrm{C}$ ). For each combination a 20 -min collection period was followed by $15-20 \mathrm{~min}$ to achieve a new steady state.

Another seven tubules were alternately perfused and bathed with isotonic perfusate (perfusion $A$ and bath $C$ ) and hypotonic, low $\mathrm{NaCl}$ perfusate (perfusion $\mathrm{B}$ and bath $\mathrm{C}$ ). In each experiment a 20-25-min collection period with one combination was followed by a 10-15-min equilibration period to achieve a new steady state with the second combination before obtaining a 20-25 min collection.

In all subsequent protocols of this study tubules were perfused and bathed with solutions identical in composition, osmolality, and $\mathrm{pH}$ to perfusion $\mathrm{B}$ and bath $\mathrm{C}$ (Table I), i.e., hypotonic, low $\mathrm{NaCl}$ perfusion.

PTH. In four tubules control collections were obtained during the initial 20-30 min of perfusion. Then, PTH (Wilson Laboratories, $1,200 \mathrm{U} / \mathrm{mg}$ ) was added to the bath in a final concentration of $0.1 \mathrm{U} / \mathrm{ml}$. Collections were obtained during 40-50 min following PTH. In another seven tubules the same procedure was repeated but $1.0 \mathrm{U} / \mathrm{ml}$ of PTH was added to the bath.

Dibutyryl cyclic AMP. In six tubules control collections were obtained during the first 20-25 min of perfusion. Then, dibutyryl-3',5'-cyclic AMP (Schwartz Bioresearch, Inc., Orangeburg, NY) was added to the bath in a final concentration of $0.1 \mathrm{mM}$. Collections were obtained during 40-45 min of perfusion following the cyclic nucleotide.

\section{CALCIUM AND MAGNESIUM CONCENTRATION GRADIENTS}

High calcium lumen. To determine the effects of increasing luminal calcium concentration on the tubular parameters under study, six tubules were perfused and bathed in a random order with either a hypotonic perfusate containing $1.25 \mathrm{mM} \mathrm{Ca}^{++}$as in Table I or an otherwise identical solution containing $2.5 \mathrm{mM} \mathrm{Ca}^{++}$. Each tubule was perfused with one gradient for 20-25 min and samples were collected. Then the perfusate solution was changed. 15-20 min were allowed to reach a new steady state. Then samples were collected over a subsequent 20-25-min period.

TABLE I

Composition of Perfusion and Bathing Solutions

\begin{tabular}{lccccc}
\hline & \multicolumn{2}{c}{ Perfusion solutions } & & \multicolumn{2}{c}{ Bathing solutions } \\
\cline { 2 - 3 } \cline { 5 - 6 } & $\mathrm{A}$ & $\mathrm{B}$ & & $\mathrm{C}$ & $\mathrm{D}$ \\
\hline Sodium & 145.7 & 59.1 & & 146.4 & 38.0 \\
Potassium & 5.03 & 4.96 & & 5.00 & 4.88 \\
Chloride & 133.9 & 58.2 & & 120.1 & 7.8 \\
Calcium & 1.03 & 1.00 & & 1.03 & 1.01 \\
Phosphate & 1.28 & 1.28 & & 1.29 & 1.29 \\
Magnesium & 0.73 & 0.70 & & 0.72 & 0.68 \\
Bicarbonate & & & & 25.0 & 25.0 \\
Acetate & & & & 10.0 & 10.0 \\
Sulfate & & & & 1.5 & 1.5 \\
Dextrose & & & & 5.5 & 5.5 \\
Mannitol & & & & 200 \\
Osmolality & & & & \\
$\quad$ mosmol $/ \mathrm{kg} \mathrm{H}_{2} \mathrm{O}$ ) & 289.8 & 134.2 & 292.3 & 301.5 \\
\hline
\end{tabular}

All concentrations, with the exception of osmolality, are expressed as millimolar.
High magnesium lumen. To study the effects of increased luminal magnesium on transport parameters, five tubules were perfused and bathed in a random order with either hypotonic perfusate (Table I) or an identical solution containing $1.40 \mathrm{mM} \mathrm{Mg}{ }^{++}$. The time sequence of this protocol was identical to that of the high calcium perfusion protocol described above.

High calcium or magnesium bath. To evaluate the effects of high calcium bath and/or high magnesium bath on tubular parameters five tubules were perfused with the hypotonic, low $\mathrm{NaCl}$ perfusate and bathed in isotonic bath solution containing $0.70 \mathrm{mM} \mathrm{Mg}^{++}$and $1.25 \mathrm{mM} \mathrm{Ca}^{++}$. Two to four control collections were obtained over a 15-20-min period. Then either calcium concentration or magnesium concentration in the bath was raised to 2.50 or $1.40 \mathrm{mM}$, respectively, and after a 15 -min time period for equilibration, collections were continued for a second 15-20-min period. Then the concentration of the other element was increased and the element that had been increased in the second period was restored to control concentrations. After a 15-min equilibration period, a third 15-20-min collection was obtained.

\section{Calculations}

For each tubule the data from three to six collections during a control or experimental perfusion period was averaged and the mean value used as a single data point. The statistical significance of the difference in means of the various groups was calculated using the Student's $t$ test for paired and/or unpaired observations, as appropriate. Regression analysis was used in defining linearity relationships.

The observed transepithelial PD were corrected for liquid junction potentials generated due to the differences between the ionic compositions of perfusion and bath solutions depicted in Table I. These junction potentials were calculated at $39^{\circ} \mathrm{C}$ by the method described by Bourdeau and Burg (13). The observed transepithelial PD were also corrected for the dilution potential generated due to the change in sodium concentration along the tubular length $(14,16)$ as follows. 20 tubules were first perfused with a perfusate containing $146 \mathrm{mM} \mathrm{Na}^{+}$and bathed in a solution containing 146 $\mathrm{mM} \mathrm{Na}{ }^{+}$and the PD was recorded; then the perfusate was exchanged for a solution containing $59 \mathrm{mM} \mathrm{Na}^{+}$. The difference in the observed perfusion end PD under the above conditions is due to a dilution potential caused by an $87 \mathrm{mM}$ drop in $\mathrm{Na}$ concentration. This dilution potential was $1.33 \pm 0.09 \mathrm{mV} / 10 \mathrm{mM}$ decrement in $\mathrm{Na}$ concentration in the perfusion solution. Assuming a homogeneous tubule and a direct relationship between the dilution potential and luminal $\mathrm{NaCl}$ concentration, we then calculated, for each tubule, the average $P D$ along the length of the tubule, i.e., the logarithmic mean of perfusion end PD and collecting end PD. The collection end PD was estimated as perfusion end $\mathrm{PD}+(0.133 \mathrm{mV} / \mathrm{mM} \mathrm{Na})$ (perfused $[\mathrm{Na}]$ - collected [Na]).

Net transport of the various ions was calculated as the product of the perfusion rate (calculated as the collection rate) and the difference between the concentration of that ion in perfusate and collected fluid. All transport rates were calculated as picomoles per millimeter of tubular length per minute. All data are expressed as the mean $\pm S E M$ of the number of tubules studied.

\section{RESULTS}

Effects of time. To control for the effects of time in the subsequent studies, nine tubules were perfused 
TABLE II

Effect of Time on Electrolyte Transport in CTALH

\begin{tabular}{|c|c|c|c|c|c|c|c|}
\hline & Flow rate & PD & $j_{\mathrm{Na}}$ & $\mathrm{Ja}$ & Ja. & $I_{m_{m}}$ & Jx \\
\hline & $n l / m+n$ & $m V$ & & & $p m o l / m m / m$ & & \\
\hline Period I & $\begin{array}{c}3.07 \pm 0.21 \\
(9)\end{array}$ & $\begin{array}{c}+7.9 \pm 1.7 \\
(7)\end{array}$ & $\begin{array}{c}53.8 \pm 17.5 \\
(9)\end{array}$ & $\begin{array}{c}47.4 \pm 15.1 \\
(9)\end{array}$ & $\begin{array}{c}0.43 \pm 0.01 \\
(9)\end{array}$ & $\begin{array}{c}0.37 \pm 0.07 \\
(9)\end{array}$ & $\begin{array}{c}-1.40 \pm 0.98 \\
\text { (9) }\end{array}$ \\
\hline Period II & $\begin{array}{c}2.81 \pm 0.14 \\
(9)\end{array}$ & $\begin{array}{c}+7.4 \pm 1.7 \\
(7)\end{array}$ & $\begin{array}{c}58.9 \pm 17.6 \\
(9)\end{array}$ & $\begin{array}{c}51.1 \pm 17.6 \\
(9)\end{array}$ & $\begin{array}{c}0.39 \pm 0.01 \\
(9)\end{array}$ & $\begin{array}{c}0.26 \pm 0.08 \\
(9)\end{array}$ & $\begin{array}{c}-0.27 \pm 0.83 \\
(9)\end{array}$ \\
\hline Period III & $\begin{array}{c}2.74 \pm 0.12 \\
(9)\end{array}$ & $\begin{array}{c}+6.5 \pm 0.9^{\circ} \\
(7)\end{array}$ & $\begin{array}{c}67.7 \pm 11.5 \\
(9)\end{array}$ & $\begin{array}{c}52.8 \pm 10.8 \\
(9)\end{array}$ & $\begin{array}{c}0.30 \pm 0.10^{\circ} \\
(8)\end{array}$ & $\begin{array}{c}0.27 \pm 0.01^{\bullet} \\
(9)\end{array}$ & $\begin{array}{c}-0.51 \pm 0.81 \\
(8)\end{array}$ \\
\hline
\end{tabular}

Nine tubules were perfused with isotonic perfusate for three consecutive 40-min periods. All values are given as mean \pm SEM; number in parentheses refers to numbers of tubules for which data was available. $\mathrm{J}_{\mathrm{Na}}, \mathrm{J}_{\mathrm{Cl}}, \mathrm{J}_{\mathrm{Ca}}, \mathrm{J}_{\mathrm{Mg}}$, and $\mathrm{J}_{\mathrm{K}}$ refer to the net transport of $\mathrm{Na}$, Cl, $\mathrm{Ca}, \mathrm{Mg}$, and $\mathrm{K}$.

- Asterisk indicates statistically significant difference between each mean value and the mean value for period I using a paired $t$ test.

with isotonic perfusate and bath, and data were obtained over three consecutive 40 -min collection periods. These data are shown in Table II. There was a tendency toward a fall in transepithelial PD that became significant in the third period. Net calcium and magnesium absorption also fell with time, beginning during the second $40 \mathrm{~min}$ of perfusion and becoming statistically significant during the third consecutive period of perfusion.

Effects of PD. Perfusion of 22 tubules with fluid isotonic to bath containing $146 \mathrm{mM} \mathrm{NaCl}, 1.25 \mathrm{mM}$ calcium, and $0.70 \mathrm{mM}$ magnesium at a mean rate of $3.62 \pm 0.27 \mathrm{nl} / \mathrm{min}$ resulted in a mean transepithelial PD of $+8.8 \pm 0.7 \mathrm{mV}$, lumen positive. There was net absorption of calcium and magnesium representing $16.2 \pm 2.1$ and $18.8 \pm 2.0 \%$ of the delivered load, respectively.
In 42 tubules studied in the various protocols, perfusion with a solution hypotonic to the bath, containing $59 \mathrm{mM} \mathrm{NaCl}$, resulted in a significantly increased PD and an increased net absorptive rate of calcium and magnesium and potassium when compared with the data obtained with isotonic perfusates (Table III). 13 of these tubules, not shown separately in the table were initially perfused with isotonic perfusate. In this group, the PD increased from $7.6 \pm 0.9 \mathrm{mV}$ to $15.8 \pm 1.2 \mathrm{mV}$, lumen positive $(P<0.001)$, associated with an increase in net absorption of calcium from $0.29 \pm 0.10$ to $0.66 \pm 0.11 \mathrm{pmol} / \mathrm{mm}$ per $\min (n=9, P<0.001)$, and an increase in net absorption of magnesium from $0.28 \pm 0.03$ to $0.54 \pm 0.08 \mathrm{pmol} / \mathrm{mm}$ per $\min (n=13$, $P<0.001$ ).

Perfusion of six tubules with perfusion solution A to which luminal $50 \mu \mathrm{M}$ furosemide was added and

TABLE III

Effect of PD on Electrolyte Transport in CTALH

\begin{tabular}{|c|c|c|c|c|c|}
\hline & Flow rate & PD & Ja. & $\mathrm{J}_{\mathrm{Mz}}$ & $J_{\mathbf{k}}$ \\
\hline & $n l / m i n$ & $\boldsymbol{m V}$ & & $\mathrm{pmol} / \mathrm{mm} / \mathrm{min}$ & \\
\hline Isotonic perfusate & $\begin{array}{c}3.62 \pm 0.27 \\
(22)\end{array}$ & $\begin{array}{c}+8.8 \pm 0.7 \\
\quad(20)\end{array}$ & $\begin{array}{c}0.36 \pm 0.07 \\
(18)\end{array}$ & $\begin{array}{l}0.32 \pm 0.06 \\
(21)\end{array}$ & $\begin{array}{c}-0.16 \pm 0.45 \\
(22)\end{array}$ \\
\hline Hypotonic perfusate & $\begin{array}{c}4.43 \pm 0.24 \\
(42)\end{array}$ & $\begin{array}{c}+13.6 \pm 0.8^{\circ} \\
(42)\end{array}$ & $\begin{array}{l}0.56 \pm 0.05^{\circ} \\
\quad(37)\end{array}$ & $\begin{array}{c}0.45 \pm 0.04^{\circ} \\
(42)\end{array}$ & $\begin{array}{c}2.06 \pm 0.24^{\circ} \\
(40)\end{array}$ \\
\hline $\begin{array}{l}\text { Isotonic, low } \mathrm{NaCl} \\
\text { bath }\end{array}$ & $\begin{array}{c}3.95 \pm 0.52 \\
(6)\end{array}$ & $\begin{array}{c}-10.4 \pm 2.1^{\circ} \\
(6)\end{array}$ & $\begin{array}{c}-0.49 \pm 0.05^{\circ} \\
(6)\end{array}$ & $\begin{array}{c}-0.45 \pm 0.08^{\circ} \\
(6)\end{array}$ & $\begin{array}{c}-1.49 \pm 0.36^{\circ} \\
(6)\end{array}$ \\
\hline
\end{tabular}

22 tubules were perfused with perfusate isotonic to bath. Some of these 22 tubules as well as a separate group of tubules totaling 42 tubules were perfused with the perfusate hypotonic to the bath and 6 tubules were perfused in an isotonic, low $\mathrm{NaCl}$ bath, and $50 \mu \mathrm{M}$ furosemide added to the perfusate. All data are given as the mean $\pm S E M$ and number in parenthesis refers to numbers of tubules for which data was available.

- Asterisk indicates statistically significant differences between each value and the value in the other two groups using an unpaired $t$ test. $\mathrm{J}_{\mathrm{Ca}}, \mathrm{J}_{\mathrm{Mg}}$, and $\mathrm{J}_{\mathrm{K}}$ refer to the net transport of $\mathrm{Ca}, \mathrm{Mg}$, and $\mathrm{K}$. 


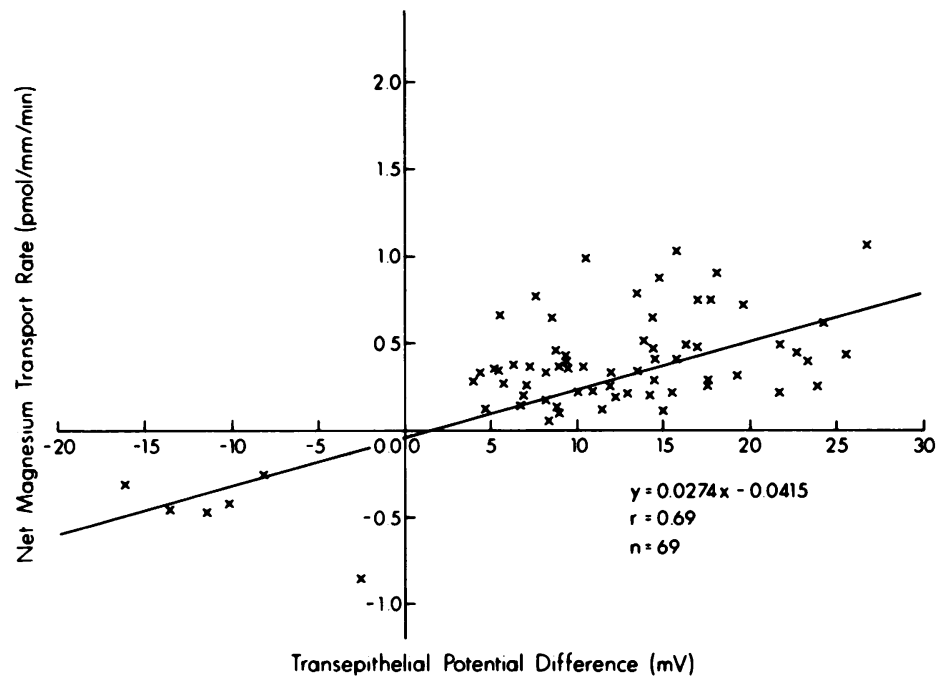

FIGURE 1 Relationship between net magnesium transport and transepithelial PD. Each point represents the mean value for two to four collections during a $15-30$-min period for a single tubule. The values for transepithelial PD are corrected as described in Methods for dilution potential and expected change along the tubule as calculated from the sodium concentration in collected fluid. A minus value for magnesium transport indicates net secretion and a positive value net absorption. For transepithelial PD, minus refers to lumen negative and plus, lumen positive. Tubules were exposed to isotonic perfusate $(n=21)$, hypotonic, low $\mathrm{NaCl}$ perfusate $(n=42)$, or isotonic, low $\mathrm{NaCl}$ bath with luminal furosemide, $50 \mu \mathrm{M}(n=6)$, to provide the range of voltages.

an isotonic, low $\mathrm{NaCl}$ bath resulted in a negative luminal voltage with respect to the bath and net secretion of calcium, magnesium, and potassium as shown in Table III. In those six tubules, net transport of calcium and magnesium under the three perfusion conditions were $0.58 \pm 0.11,0.18 \pm 0.08,-0.49 \pm 0.05 \mathrm{pmol} / \mathrm{mm}$ per min for calcium and $0.50 \pm 0.10,0.24 \pm 0.05$, and $-0.45 \pm 0.08 \mathrm{pmol} / \mathrm{mm}$ per min for magnesium. The mean values for transepithelial voltages in these six tubules during the three different conditions were $+15.7 \pm 2.6$, $+6.9 \pm 1.2$, and $-10.4 \pm 2.1 \mathrm{mV}$, respectively. Net calcium and net magnesium transport as

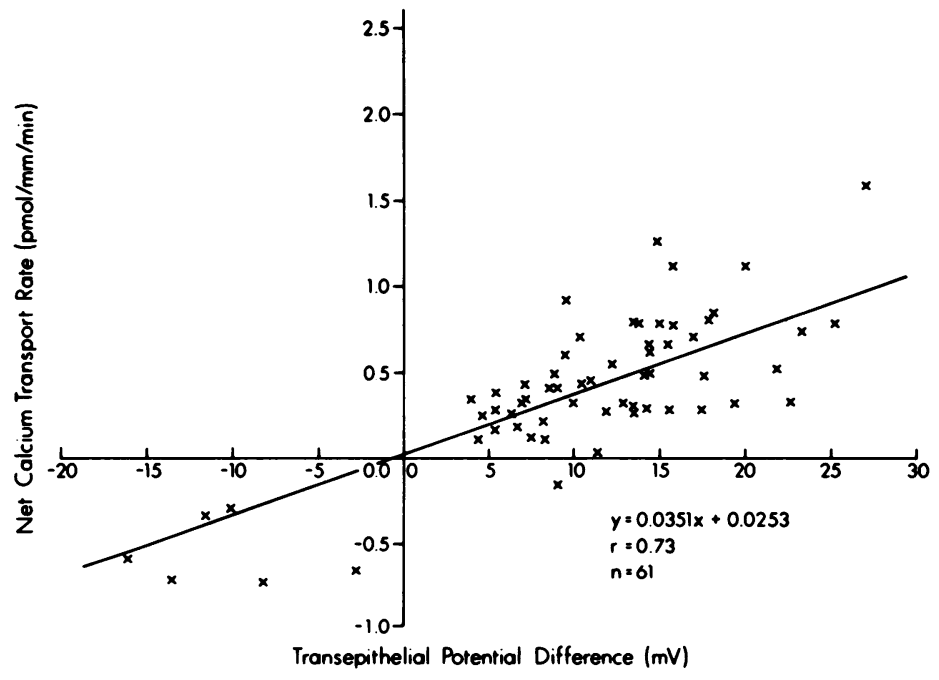

FIGURE 2 Relationship between net calcium transport and transepithelial PD. See legend to Fig. 1. Tubules were exposed to isotonic perfusate $(n=18)$, hypotonic, low $\mathrm{NaCl}$ perfusate $(n=37)$, or isotonic, low $\mathrm{NaCl}$ bath with luminal furosemide, $50 \mu \mathrm{M}(n=6)$. 


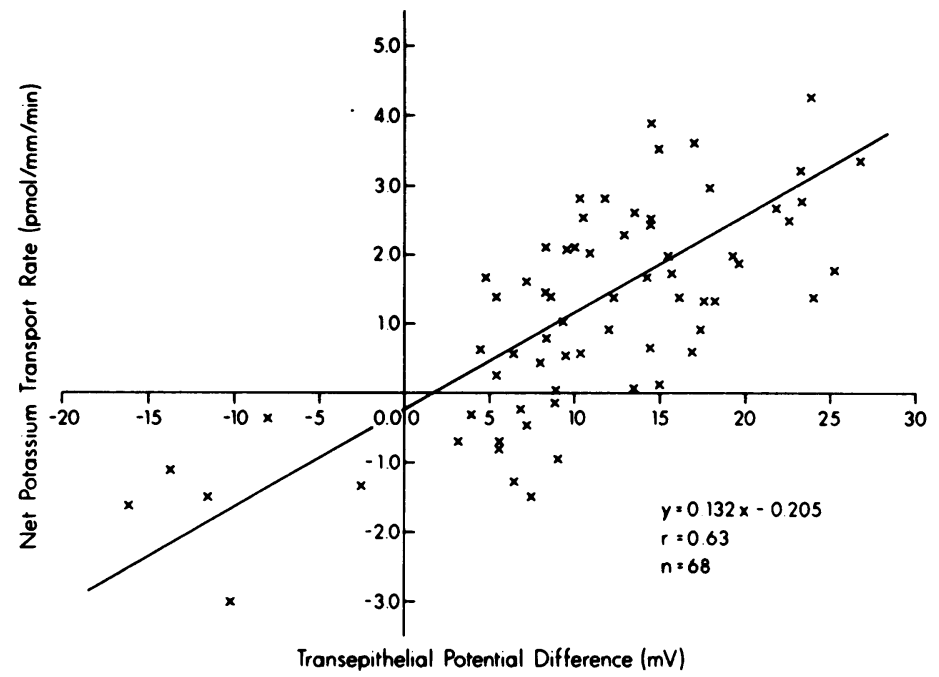

Figure 3 Relationship between net potassium transport and transepithelial PD. See legend to Fig. 1. Tubules were exposed to isotonic perfusate $(n=22)$, hypotonic, low $\mathrm{NaCl}$ perfusate $(n=40)$, or isotonic, low $\mathrm{NaCl}$ bath with luminal furosemide, $50 \mu \mathrm{M}(n=6)$.

well as PD for each of the protocols was significantly different from the other two $(P<0.05)$.

Linear regression analysis of net calcium, magnesium, and potassium transport vs. transepithelial voltage for all of the tubules studied under the different conditions showed similar results as depicted in Figs. 1,2 , and 3. For calcium the slope equaled 0.0351 $\mathrm{pmol} / \mathrm{mm}$ per min per $\mathrm{mV}$ and the intercept +0.0253 $(r=0.73, P<0.001)$. For magnesium the slope equaled $0.0274 \mathrm{pmol} / \mathrm{mm}$ per minute per $\mathrm{mV}$ and the intercept $-0.0415(r=0.69, P<0.001)$. For potassium the slope equaled $0.1320 \mathrm{pmol} / \mathrm{mm}$ per minute per millivolt and the intercept $-0.2050(r=0.63, P<0.001)$.

Effects of PTH and cyclic AMP. In four tubules, PTH was added to the bath in a final concentration of $100 \mathrm{mU} / \mathrm{ml}$ and no effects on transport of any ion were observed consistent with previously published studies at this dose level (11). Subsequently, PTH was added to the bath in a final concentration of $1.0 \mathrm{U} / \mathrm{ml}$ following a 30 -min control period during perfusion with hypotonic low $\mathrm{NaCl}$ perfusate in seven tubules. The data are shown in Table IV. There was no effect upon PD or potassium transport while net calcium absorption increased from $0.44 \pm 0.10$ to $0.69 \pm 0.14$ $\mathrm{pmol} / \mathrm{mm}$ per min $(P<0.01)$. Similarly as shown in Table V, dibutyryl cyclic AMP added to the bath in six tubules significantly increased both calcium (from $0.52 \pm 0.08$ to $0.97 \pm 0.08 \mathrm{pmol} / \mathrm{mm}$ per $\min , P<0.001$ ), and magnesium (from $0.34 \pm 0.06$ to $0.63 \pm 0.06 \mathrm{pmol}$ / $\mathrm{mm}$ per min, $P<0.001$ ) absorption, but had no effect upon transport of potassium, although PD decreased slightly. The time-course of these changes in calcium and magnesium transport are shown in Fig. 4 for PTH and Fig. 5 for dibutyryl cyclic AMP. In both instances, effects were evident within the first $10 \mathrm{~min}$ and sustained throughout the 40-50-min experimental period.

Effects of concentration differences. To evaluate the effects of concentration difference as well as pos-

TABLE IV

Effects of PTH on Electrolyte Transport in CTALH

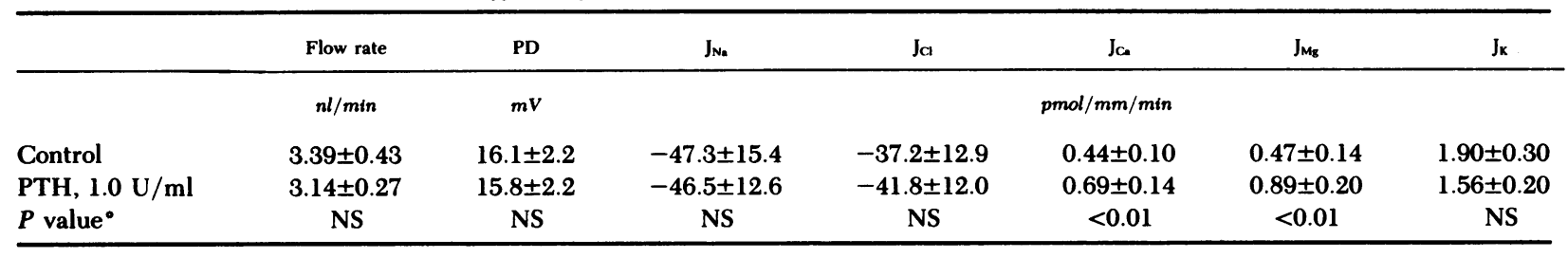

Control data were obtained in seven tubules during a 20-30-min period of perfusion with hypotonic, low $\mathrm{NaCl}$ perfusate. PTH was then added to the bath and experimental data obtained during a subsequent $40-50$-min period. All values are the mean $\pm S E M$ for each group. - $P$ value denotes significance of the difference between control and experimental periods using a paired $t$ test. $\mathrm{J}_{\mathrm{Na}}$, $\mathrm{J}_{\mathrm{Cl}}$, $\mathrm{J}_{\mathrm{Ca}}, \mathrm{J}_{\mathrm{Mg}}$, and $\mathrm{J}_{\mathrm{K}}$ refer to the net transport of these elements. 
TABLE V

Effects of Dibutyryl Cyclic AMP on Electrolyte Transport in CTALH

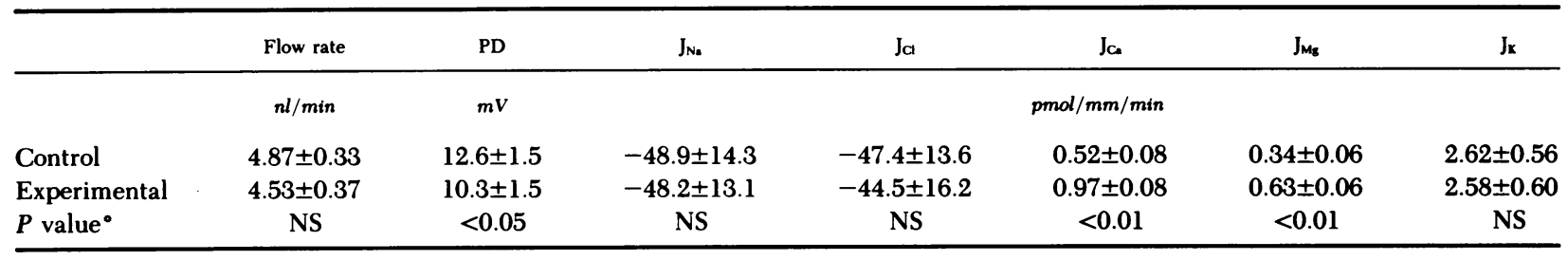

Control data were obtained in six tubules during a 20-30-min period of perfusion with hypotonic, low NaCl perfusate. Dibutyryl cyclic AMP was then added to the bath (final concentration $0.1 \mathrm{mM}$ ) and experimental collections obtained over a subsequent 40-50-min period. All data given as mean $\pm \mathrm{SEM}$ for each group.

- $P$ value denotes significance of the difference between control and experimental periods by paired $t$ test. $J_{\mathrm{Na}}, J_{\mathrm{Cl}}, \mathrm{J}_{\mathrm{Ca}}, \mathrm{J}_{\mathrm{Mg}}$, and $\mathrm{J}_{\mathrm{K}}$ refer to the net transport of these elements.

sible interactions between calcium and magnesium absorption, transport was evaluated during a control phase and after alteration of calcium or magnesium concentration in the bath and lumen. The effects of
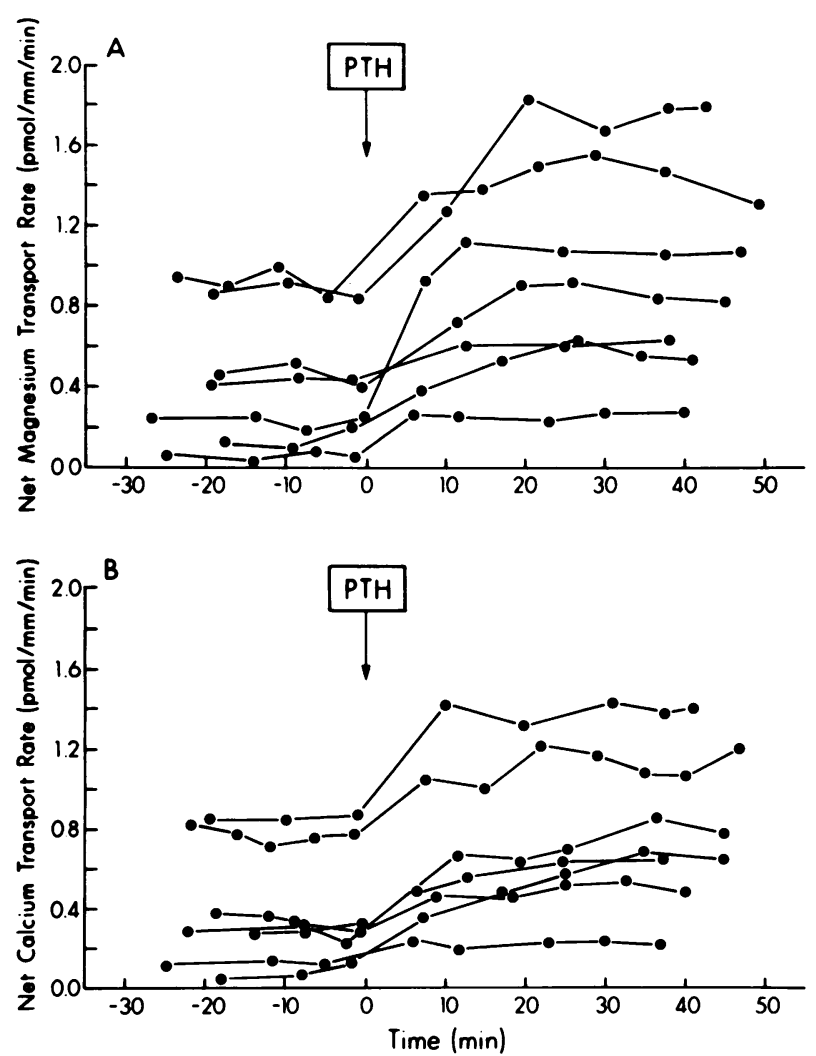

Figure 4 Time-course of the effects of PTH upon net magnesium (A) and net calcium (B) transport. In each of seven CTALH, perfused with hypotonic, low $\mathrm{NaCl}$ perfusate, control measurements were obtained at $\sim 5-10$-min intervals for 20-30 min before and 40-50 min after the addition of PTH, $1.0 \mathrm{mU} / \mathrm{ml}$, to the bath. In each case, there was an immediate increase in calcium and magnesium absorption. The mean data are described in Table IV. alterations in bath concentration are shown in Fig. 6 . Increasing the bath calcium concentration from 1.25 $\mathrm{mM}$ to $2.50 \mathrm{mM}$ in five tubules perfused with hypotonic, low $\mathrm{NaCl}$ perfusate, significantly inhibited net
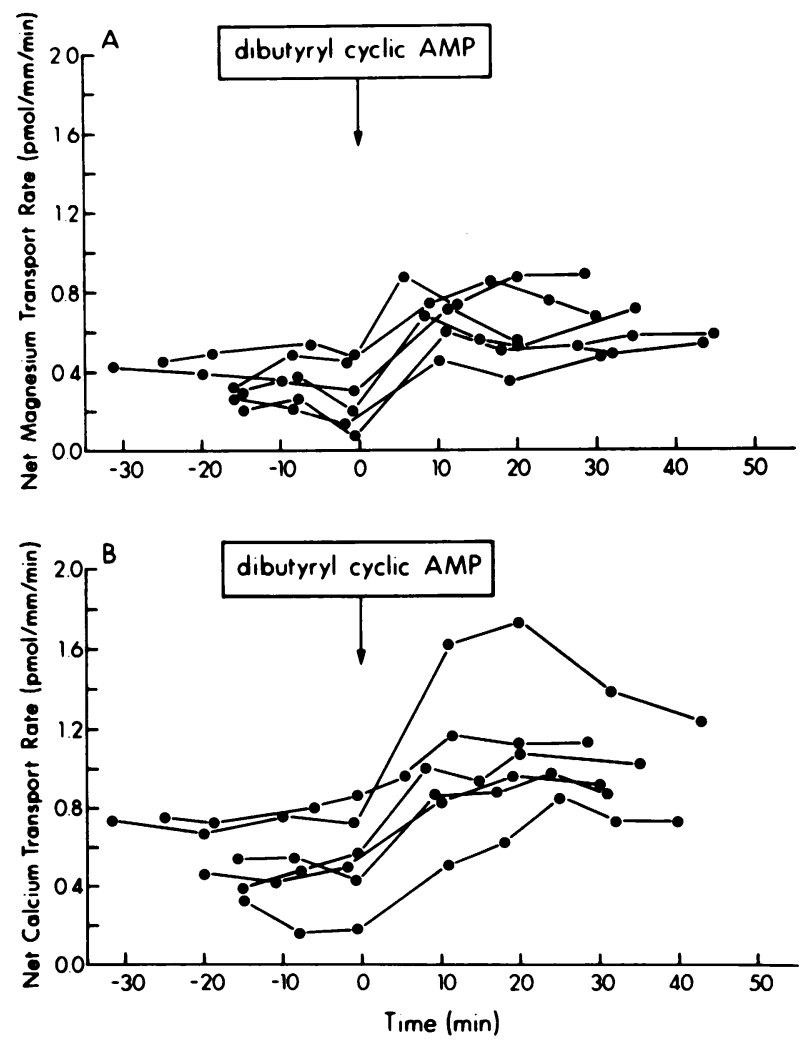

Figure 5 Time-course of the effects of dibutyryl cyclic AMP upon net magnesium (A) and net calcium (B) transport In each of six CTALH perfused with hypotonic, low $\mathrm{NaCl}$ perfusate, control measurements were obtained at $\sim 5-10$ min intervals for 20-30 min before and 40-50 min after the addition of $0.1 \mathrm{mM}$ dibutyryl cyclic AMP to the bath. In each case, there was an immediate increase in both calcium and magnesium absorption. The mean data are described in Table V. 
A CALCIUM TRANSPORT

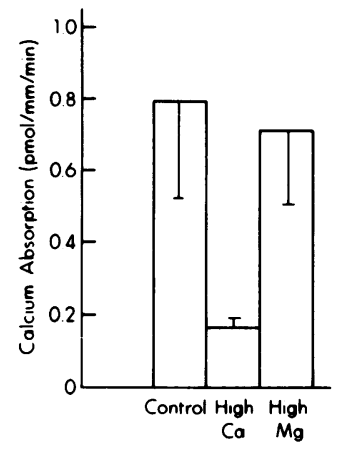

B MAGNESIUM TRANSPORT

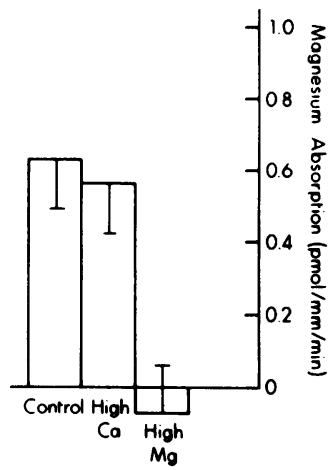

FIGURE 6 Effects of increasing bath concentration of calcium and magnesium upon net calcium absorption (A) and net magnesium absorption (B). In five tubules perfused with hypotonic, low $\mathrm{NaCl}$ perfusate, two to four control collections were obtained over a 15-20-min period with bath concentrations of $1.25 \mathrm{mM} \mathrm{Ca}$ and $0.70 \mathrm{mM} \mathrm{Mg}$. Then either calcium concentration or magnesium concentration in the bath was increased to $2.50 \mathrm{mM}$ or $1.40 \mathrm{mM}$, respectively, and after a 15-min time period to reach a new steady state, collections were continued for a second 15-20-min period. In the third collection period, the concentration of the other element was increased and the element that had been increased in the second period was restored to control concentrations. After a 15-min time period to reach a new steady state, collections were made for another 15-20-min period. The data are given as the mean \pm SEM for each period. Calcium transport $(A)$ was significantly $(P<0.05)$ reduced by increasing bath calcium concentration, but was unaffected by increasing bath magnesium. Magnesium transport (B) was inhibited by increasing bath magnesium $(P<0.01)$, but was unaffected by increasing bath calcium.

calcium absorption from $0.79 \pm 0.27$ to $0.16 \pm 0.02 \mathrm{pmol} /$ $\mathrm{mm}$ per $\min (P<0.001)$ and magnesium transport was unaffected $(0.63 \pm 0.15$ vs. $0.56 \pm 0.14 \mathrm{pmol} / \mathrm{mm}$ per $\mathrm{min})$. Increasing bath magnesium concentration to $1.40 \mathrm{mM}$ while restoring bath calcium to $1.25 \mathrm{mM}$ resulted in restoration of calcium transport, while magnesium absorption fell significantly from $0.56 \pm 0.14$ to $-0.09 \pm 0.13 \mathrm{pmol} / \mathrm{mm}$ per $\min (P<0.001)$. PD fell from $15.6 \pm 3.9 \mathrm{mV}$ during control, to $13.5 \pm 3.5 \mathrm{mV}$ $(P<.05)$ during high calcium, and $13.6 \pm 3.4 \mathrm{mV}(P$ $<.05)$ during high magnesium. Neither increasing the bath calcium nor the magnesium concentration had any detectable effect upon potassium transport.

The effects of changes in luminal concentration of calcium and magnesium were studied in separate tubules and these data are shown in Fig. 7. Calcium absorption increased significantly from $0.43 \pm 0.07$ to $1.09 \pm 0.16 \mathrm{pmol} / \mathrm{mm}$ per $\min , P<0.01$, when the perfusate calcium concentration was increased from 1.25 to $2.50 \mathrm{mM}$ in six tubules perfused with hypotonic perfusate. Increasing the magnesium concentration from 0.70 to $1.40 \mathrm{mM}$ in five tubules, however, had
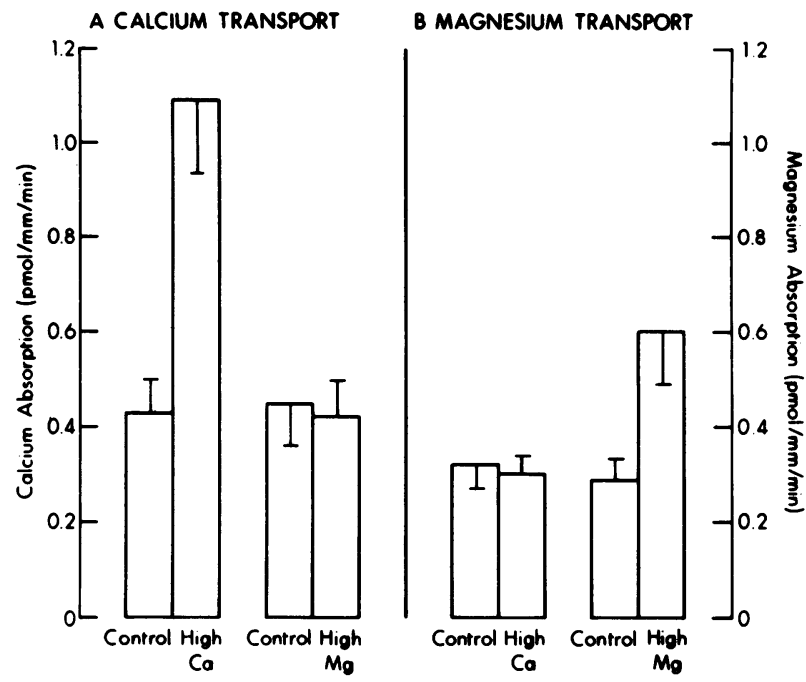

Figure 7 Effects of increasing perfusate concentration of calcium and magnesium upon net calcium absorption (A) and net magnesium absorption (B). 11 tubules were perfused with hypotonic, low $\mathrm{NaCl}$ perfusate, and two to four control collections obtained during a 20-25-min period. In six tubules, perfusate calcium concentration was increased to 2.50 $\mathrm{mM}$ and in five, perfusate magnesium concentration was increased to $1.40 \mathrm{mM}$, and after a $15-20-\mathrm{min}$ time period to reach a new steady state, collections were continued for a second 20-25-min period. The data are given as the mean $\pm S E M$ for each group of tubules during the control and experimental periods. Calcium transport (A) increased with increasing perfusate calcium concentration $(P<0.01)$, but was not affected by increasing magnesium concentration. Similarly, magnesium absorption (B) was increased by increasing magnesium concentration $(P<0.02)$, but was unaffected by increasing perfusate calcium concentration.

no effect upon calcium transport. Conversely, increasing calcium concentration had no effect upon magnesium absorption, while increasing the magnesium concentration in the perfusate increased magnesium absorption significantly from $0.29 \pm 0.04$ to $0.60 \pm 0.11 \mathrm{pmol} / \mathrm{mm}$ per $\mathrm{min}, P<0.02$. In both circumstances, PD fell slightly from $15.4 \pm 1.5$ to $12.5 \pm 1.7$ $\mathrm{mV}, P<0.001$, with increased luminal calcium, and from $14.4 \pm 1.9$ to $12.4 \pm 1.8 \mathrm{mV}, P<0.05$, with increased luminal magnesium. There were no significant effects observed upon potassium transport.

\section{DISCUSSION}

These studies, representing the first direct evaluation of magnesium transport in the CTALH, indicate important effects of voltage, concentration, and PTH and dibutyryl cyclic AMP. There was a clear relationship between voltage and net transport such that with reversal of the voltage net secretion of magnesium was observed. At no time was net absorption found in the 
absence of a favorable electrical gradient and thus we found no direct evidence for active magnesium transport. However, since we did not examine transport in the absence of net driving forces, i.e., at a transepithelial PD of zero in the absence of a concentration gradient, we cannot exclude a component of active transport. The high lumen positive voltage expected in vivo, from a combination of chloride transport and greater sodium than chloride permeability, could play a major role in regulating magnesium transport.

Previous studies in vivo have demonstrated increased magnesium absorption with an increase in delivered load to the loop of Henle (6). Our studies are consistent with this observation and demonstrate a proportional increase in transport with increases in perfusate concentration in the thick ascending limb. Increasing magnesium perfusate concentration had no effect upon potassium or calcium transport and produced only a slight change in transpithelial PD. Similarly, increasing calcium concentration was associated with an increase in calcium absorption and no detectable effect upon magnesium transport. These data are compatible with the thesis suggested by Quamme and Dirks (9) that magnesium entry across the mucosal membrane is passive and gradient dependent, and provide no evidence for interaction of magnesium with other ions.

When magnesium concentration in the bath was increased twofold, there was a significant reduction in net magnesium absorption. Quamme and Dirks (6), however, demonstrated in vivo that hypermagnesemia, which is considered analogous to an increase in bath magnesium, produced an inhibition of net magnesium absorption, which was independent of the luminal concentration. In neither our studies, nor the in vivo studies (6), was there evidence of major alterations in sodium transport, but important differences in the two studies are evident with respect to calcium transport. In vivo hypermagnesemia produced an inhibition of calcium reabsorption and similarly hypercalcemia was associated with reduced fractional and absolute absorption of magnesium in the perfused segment (6). On the basis of these observations, Quamme and Dirks $(6,9)$ have postulated a magnesium transport system that includes a competition between magnesium and calcium for transport, operating on the contraluminal surface of the ascending limb cell. The difference between the in vivo data and the present results may be due to species differences. There are also obviously a number of differences in the two techniques that could account for these results. The most obvious are that the microperfusion studies measure transport across the entire middle portion of the nephron, including the pars recta, where studies of magnesium transport have not yet been done. In addition to inability to localize transport effects directly to the CTALH, it is possible that in vivo studies might reflect other systemic and hemodynamic effects of hypercalcemia and hypermagnesemia, which would not be operative in the isolated tubule system. It should also be pointed out, however, that our studies were carried out at only two bath concentrations of calcium and magnesium. While the concentration range we used included the values for ultrafiltrable calcium and magnesium obtained in the in vivo studies, it is possible that higher values were achieved for the interstitial concentration of these ions. It remains possible, therefore, that at higher bath concentrations, interactions between calcium and magnesium would be observed in vitro. To the extent that the concentration ranges utilized in our studies include the expected values in a normocalcemic, normomagnesemic animal, the data do not provide for an important role of a $\mathrm{Ca}-\mathrm{Mg}$ competitive transport mechanism in the CTALH. As calcium transport may differ in the cortical and medullary portions of the TALH, it is possible that the discrepancy between in vivo data and the present results may reside in a different interaction between calcium and magnesium transport in the medullary TALH. Because of the hypotonic perfusate, our studies were carried out in the relative absence of net sodium or chloride reabsorption. If the proposed interaction involved a separate pathway linked to sodium or chloride, it may not have been detected therefore in our studies. This seems unlikely, however, as no effects of either hypercalcemia (7), or hypermagnesemia (6) were noted upon loop sodium transport in in vivo microperfusion studies.

Previous studies, using a variety of techniques, have shown that PTH stimulates adenylate cyclase activity and reduces urinary excretion of calcium and magnesium (17-21). The data for the effects of PTH on magnesium excretion have been less consistent than those for calcium, but in some studies hypercalcemia may have obscured an independent effect upon magnesium. The site of action of PTH upon calcium transport has been shown to include the ascending limb of Henle's loop (22), as well as the distal tubule and terminal portions of the nephron $(11,17,23-25)$. The site of PTH enhancement of magnesium transport has not been as extensively studied. Harris et al. (26) demonstrated effects of PTH to enhance magensium reabsorption in the loop of Henle in the thyroparathyroidectomized hamster (26). Similarly, Quamme (6, 8) demonstrated PTH-induced magnesium reabsorption when transport had been initially reduced by either hypermagnesemia or furosemide. Our data provide the first direct demonstration of stimulation of magnesium absorption in the CTALH by PTH and by dibutyryl cyclic AMP. We were unable to detect any 
change with smaller doses of PTH $(0.1 \mathrm{U} / \mathrm{ml})$, similar to data previously published for calcium (11). The requirement for higher doses of PTH in this segment as compared with distal portions of the nephron is compatible with the relative activities in these segments described by Chabardes et al. (27) in the rabbit. As dibutyryl cyclic AMP had identical effects, the data are compatible with mediation of the action of PTH by altering the intracellular concentration of cyclic AMP. Our data offer no new insights into the mechanism of action of PTH in this segment. Under the conditions studied, either stimulation of active transport or an increase in passive permeability could adequately explain our observations.

Our data on calcium transport are qualitatively similar to those previously published by Bourdeau and Burg $(13,22)$. Measuring net transport with the electron probe rather than unidirectional fluxes, we found that calcium transport was strongly voltage dependent and enhanced by large doses of PTH; however, regression analysis of net calcium transport vs. voltage revealed a slope significantly steeper than that reported by these authors. The differences probably relate to the fact that Bordeau and Burg calculated their linear regression using groups of tubules perfused at significantly different flow rates and estimated the collected fluid sodium concentration. In our studies, all flows were relatively constant and the PD was calculated based upon actual measurements of collected sodium concentration in each tubule. We found no evidence for active calcium transport, as defined by net absorption in the absence of an electrochemical gradient, and in addition we demonstrated that there is a striking influence of calcium concentration upon net transport. Thus, similar to magnesium, increasing luminal or bath calcium concentration twofold, produced opposite changes in net transport without large changes in transepithelial PD.

Micropuncture studies in the rat $(28,29)$, and isolated perfusion studies of pars recta (30), suggest that there is a large addition of potassium to the luminal fluid before the ascending limb of Henle's loop and that the bulk of this secreted potassium is reabsorbed before the early distal tubule. While these studies were not specifically designed to evaluate the mechanism of potassium transport in this segment, the data do provide some useful information. They demonstrate that potassium can be both reabsorbed and secreted as suggested previously (31), and that net transport similar to calcium and magnesium is highly voltage dependent. Under conditions characterized by a high lumen positive voltage and the absence of a concentration gradient, potassium is reabsorbed at a rate of $2 \mathrm{pmol} / \mathrm{mm}$ per $\mathrm{min}, \sim 10 \%$ of the delivered load. It is likely that increasing the luminal potassium con- centration several fold, as is presumed to occur via secretion of potassium between the proximal convoluted tubule and tip of the loop of Henle, could markedly increase the rate of transport. This, however, remains to be directly evaluated.

In summary, the data demonstrate voltage-dependent magnesium transport in the CTALH. Transport is also influenced by both luminal and bath concentration, and reabsorption is stimulated by PTH and dibutyryl cyclic AMP. These studies and others suggest that the positive transepithelial voltage in the thick ascending limb is an important driving force for net reabsorption of calcium, magnesium, and potassium in this segment. The data do not provide support for either the concept of a calcium-magnesium interaction, or a unique transport system for magnesium, whose modulation would alter net transport independent of changes in passive forces. Whether or not PTH is physiologically important in the regulation of transport in this segment, the role of other hormones, such as calcitonin, and differences between the CTALH and other components of the segment of the nephron between the proximal convoluted tubule and distal tubule, remain to be explored.

\section{ACKNOWLEDGMENTS}

The authors would like to thank Ms. Dorothy Senesky, Marva Lee, Phyllis May, Sandra Markus, Barbara Ladenson, and Mr. John Schell for their technical assistance.

This study was supported, in part, by a National Institutes of Health grant 5-R01-HL00340 from the National Heart and Lung Institute, and National Institute of Health training grant 5-T32-AM07006 from the National Institute of Arthritis, Metabolic, and Digestive Diseases.

\section{REFERENCES}

1. Wen, S. F., R. L. Evanson, and J. H. Dirks. 1970. Micropuncture study of magnesium transport in proximal and distal tubule of the dog. Am. J. Physiol. 219: 570576.

2. Brunette, M. G., N. Vigneault, and S. Carriere. 1974. Micropuncture study of magnesium transport along the nephron in the young rat. Am. J. Physiol. 227: 891-896.

3. LeGrimellec, C., N. Roinel, and F. Morel. 1973. Simultaneous $\mathrm{Mg}, \mathrm{Ca}, \mathrm{P}, \mathrm{K}, \mathrm{Na}$, and $\mathrm{Cl}$ analysis in rat tubular fluid. I. During perfusion of either inulin or ferrocyanide. Pfluegers Arch. Eur. Physiol. 340: 181-196.

4. LeGrimellec, C., N. Roinel, and F. Morel. 1974. Simultaneous $\mathrm{Mg}, \mathrm{Ca}, \mathrm{P}, \mathrm{K}, \mathrm{Na}$, and $\mathrm{Cl}$ analysis in rat tubular fluid. III. During acute Ca plasma loading. Pfluegers Arch. Eur. Physiol. 346: 171-180.

5. DeRouffignac, C., F. Morel, N. Moss, and N. Roinel. 1973. Micropuncture study of water and electrolyte movement along the loop of Henle in Psammomys, with special reference to magnesium, calcium, and phosphate. Pfluegers Arch. Eur. Physiol. 344: 309-326.

6. Quamme, G. A., and J. H. Dirks. 1980. Intraluminal and contraluminal magnesium on magnesium and calcium transfer in the rat nephron. Am. J. Physiol. 238: F187F198. 
7. Blassnig, R., and G. A. Quamme. 1978. Effect of hypercalcemia on calcium and magnesium transport along the loop of Henle and distal tubule. Clin. Res. 26: 867a.

8. Quamme, G. A. 1978. Effect of intraluminal furosemide on calcium and magnesium transport in the loop of Henle and the role of PTH. Kidney Int. 14: 642a

9. Quamme, G. A., and J. H. Dirks. 1980. Editorial review. Magnesium transport in the nephron. Am. J. Physiol. 239: F393-F401.

10. Burg, M. B., J. Grantham, M. Abramow, and J. Orloff. 1966. Preparation and study of fragments of single rabbit nephrons. Am. J. Physiol. 210: 1293-1298.

11. Shareghi, G. R., and L. C. Stoner. 1978. Calcium transport across segments of the rabbit distal nephron in vitro. Am. J. Physiol. 235: F367-F375.

12. Agus, Z. S., P. J. S. Chiu, and M. Goldberg. 1977. Regulation of urinary calcium excretion in the rat. Am. J. Physiol. 232: F545-F549.

13. Bordeau, J. E., and M. B. Burg. 1979. Voltage dependence of calcium transport in the thick ascending limb of Henle's loop. Am. J. Physiol. 236: F357-F364.

14. Burg, M. B., and N. Green. 1973. Function of the thick ascending limb of Henle's loop. Am. J. Physiol. 224: 659-668.

15. Burg, M. B., L. C. Stoner, J. Cardinal, and N. Green. 1973. Furosemide effect on isolated perfused tubules. Am. J. Physiol. 225: 119-124.

16. Rocha, A. J., and J. P. Kokko. 1973. Sodium chloride and water transport in the medullary thick ascending limb of Henle. Evidence for active chloride transport. J. Clin. Invest. 52: 612-623.

17. Agus, Z. S., L. B. Gardner, L. H. Beck, and M. Goldberg. 1973. Effects of parathyroid hormone on renal tubular reabsorption of calcium, sodium, and phosphate. Am. J. Physiol. 224: 1143-1148.

18. Burnatowska, M. A., C. A. Harris, R. A. L. Sutton, and J. H. Dirks. 1977. Effects of PTH and cAMP on renal handling of calcium, magnesium, and phosphate in the hamster. Am. J. Physiol. 233: F514-F518.

19. MacIntyre, I., S. Boss, and V. A. Troughton. 1963. Parathyroid hormone and magnesium homeostasis. Nature (Lond.). 198: 1058-1060.

20. Bethune, J. E., R. A. Turpin, and H. Inque. 1968. Effect of parathyroid extract on divalent ion excretion in man. J. Clin. Endocrinol. Metab. 28: 673-678.

21. Massry, S. G., J. W. Coburn, and C. R. Kleeman. 1969. Renal handling of magnesium in the dog. Am J. Physiol. 216: 1460-1467.

22. Bordeau, J. E., and M. B. Burg. 1980. Effect of PTH on calcium transport across the cortical thick ascending limb of Henle's loop. Am. J. Physiol. 239: F121-F126.

23. Sutton, R. A. L., N. L. M. Wong, and J. H. Dirks. 1976. Effects of parathyroid hormone on sodium and calcium transport in the dog nephron. Clin. Sci. Mol. Med. 51: 345-351.

24. Greger, R., F. Lang, and H. Oberleithner. 1978. Distal sites of calcium reabsorption in the rat nephron. Pfluegers Arch. Eur. Physiol. 374: 153-157.

25. Costanzo, L. S., and E. E. Windhager. 1980. Effects of PTH, ADH, and cyclic AMP on distal tubular $\mathrm{Ca}$ and Na reabsorption. Am. J. Physiol. 239: F478-F485.

26. Harris, C. A., M. A. Burnatowska, J. F. Seely, R. A. L. Sutton, G. A. Quamme, and J. H. Dirks. 1978. Effects of parathyroid hormone on electrolyte transport in the hamster nephron. Am. J. Physiol. 236: F342-348.

27. Chabardes, D., M. Imbert, A. Clique, M. Montegut, and F. Morel. 1975. PTH-sensitive adenyl cyclase activity in different segments of the rabbit nephron. Pfluegers Arch. Eur. Physiol. 354: 229-239.

28. Dobyan, D. C., F. B. Lacy, and R. L. Jamison. 1979. Suppression of potassium recycling in the renal medulla by short term potassium deprivation. Kidney Int. 16: 704-709.

29. Battilana, C. A., D. C. Dobyan, F. B. Lacy, J. Bhattacharya, P. A. Johnston, and R. L. Jamison. 1978. Effect of chronic potassium loading on potassium secretion by the pars recta or descending limb of the juxtamedullary nephron in the rat. J. Clin. Invest. 62: 1093-1103.

30. Wasserstein, A. G., and Z. S. Agus. 1980. Net $\mathrm{K}^{+}$secretion in proximal straight tubules. Proceedings of the American Society of Nephrology, 13th Annual Meeting. $154 a$.

31. Burg, M. B., and J. E. Bourdeau. 1978. Function of the thick ascending limb of Henle's loop. In New Aspects of Renal Function. H. G. Vogel and K. J. Ullrich, editors. Excerpta Medica, Amsterdam, 91-102. 